\title{
Implant Restoration Materials: An Overview
}

\author{
${ }^{1}$ Chethan Hegde, ${ }^{2}$ Krishna Prasad D, ${ }^{3}$ Deepmala S, ${ }^{4}$ Rakshith Hegde
}

${ }^{1}$ Professor, Department of Prosthodontics, AB Shetty Memorial Institute of Dental Sciences, Mangalore, Karnataka, India

${ }^{2}$ Professor and Head, Department of Prosthodontics, AB Shetty Memorial Institute of Dental Sciences, Mangalore, Karnataka, India

${ }^{3}$ Postgraduate Student, Department of Prosthodontics, AB Shetty Memorial Institute of Dental Sciences, Mangalore, Karnataka, India

${ }^{4}$ Reader, Department of Prosthodontics, AB Shetty Memorial Institute of Dental Sciences, Mangalore, Karnataka, India

Correspondence: Chethan Hegde, Department of Prosthodontics, AB Shetty Memorial Institute of Dental Sciences, Mangalore Karnataka, India, e-mail: hegdechethan@yahoo.co.in

\begin{abstract}
Implant success depends not only on successful osseointegration, but also on the harmonious integration of a crown into the dental arch. With many materials being introduced in implant dentistry, it is imperative to acquire knowledge about various materials available and understand the factors which will contribute to the success or failure of the restorations.

Keywords: Implant restorative materials, properties.
\end{abstract}

\section{INTRODUCTION}

Osseointegration and proper loading are two of the most important factors determining long-term implant treatment success. Once successful osseointegration is achieved, ${ }^{1}$ occlusal loading of osseointegrated implants through restorative materials is believed to be a determining factor in the long-term success of an implant treatment program. ${ }^{2-6}$

The restorative materials that can be used in implant dentistry are as follows: ${ }^{7}$

1. Noble metal alloys
i. Gold-platinum palladium (Au-Pt-Pd) alloys
ii. Gold-palladium-silver (Au-Pd-Ag) alloys
iii. Gold-palladium (Au-Pd) alloys
iv. Palladium-silver (Pd-Ag) alloys
v. High-palladium alloys.

2. Base metal alloys

i. Nickel chromium (Ni-Cr) alloys

ii. Cobalt-chromium (Co-Cr) alloys.

\section{Polymers}

i. Acrylic resins

ii. Composite resins.

\section{Ceramics}

i. Feldspathic porcelain

ii. Alumina based ceramics

iii. Zirconia based ceramics

iv. Lithium disilicate ceramics.
Requisites of an ideal implant restorative material

- It should be stable in the oral environment and should not undergo corrosion.

- It should fit passively over the implant abutment.

- It should be esthetic.

- It should not induce undue stresses in the implant or the bone.

- It should be biocompatible and should not induce any allergenic reaction.

- It should be easy to fabricate and handle.

- It should be easy to maintain.

- It should be cost-effective.

The restorative materials used in implant dentistry are explained as follows:

\section{Noble-metal alloys}

\section{i. Gold-Platinum-Palladium (Au-Pt-Pd) alloys}

The Au-Pt-Pd alloys were the first to be used successfully for metal-ceramic restorations; however, their use decreased after more economical alloys, were developed with significantly better mechanical properties and sag resistance.* If the alloy contains more palladium than platinum, it is referred to as a gold-palladium-platinum alloy. ${ }^{7}$ Alloys in which palladium has been eliminated are referred to as gold-platinum alloys. ${ }^{7}$

\section{Limitations}

Ideally, for alloys with solidus temperatures ${ }^{\#}$ of $1000^{\circ} \mathrm{C}$ or higher, sag deformation should be negligible ( $<1 \mathrm{~mm} / \mathrm{min})$.

\footnotetext{
* Sag is the deformation of a metal or alloy which occurs at high temperatures such as during procelain firing.

The resistance to this deformation is called sag resistance.

\# Solidus temperature is the temperature at which the last liquid solidified.
} 
Because of their high sag deformation $(>1 \mathrm{~mm})$, the use of Au-Pt-Pd alloys should be limited to full coverage metal ceramic crowns and three-unit fixed partial dentures. ${ }^{7}$

\section{ii. Gold-Palladium-Silver (Au-Pd-Ag) alloys}

The Au-Pd-Ag alloys were developed in an attempt to overcome the major disadvantages of the Au-Pt-Pd alloys: high cost, low hardness. The sag deformation of Au-PdAg alloys is $0.9 \mathrm{~mm} /$ minute and hardness is 210 to $230 \mathrm{~kg} /$ $\mathrm{mm}^{2}$ (Diamond pyramid hardness number). ${ }^{7}$

\section{Disadvantage}

The principal disadvantage of these alloys is the potential for their silver content to discolor porcelain surface (greening). This greening effect is thought to be caused by the colloidal dispersion of silver atoms entering body and incisal porcelain or the glazed surface from vapor transport or surface diffusion. ${ }^{7}$

iii. Gold-Palladium (Au-Pd) alloys

The Au-Pd (silver free) alloys were developed to address the two main problems associated with silver-containing alloys: Porcelain discoloration and a high coefficient of thermal expansion. When used with compatible porcelain, these (silver free) alloys are considered nearly ideal compared with other noble metal alloys. Due to these alloys' low silver content $(<5 \%)$, porcelain does not discolor and castability is improved. ${ }^{8} \mathrm{Au}-\mathrm{Pd}$ alloys are moderately priced. ${ }^{7}$

\section{Disadvantage}

Their only significant disadvantage is that they have a degree of thermal expansion that is incompatible with some high expansion porcelains. The alloys must possess coefficient of thermal expansion compatible with those of dental porcelains. The coefficient of thermal expansion of porcelain $=13.0$ to $14.0 \times 10^{-6} /{ }^{\circ} \mathrm{C}$ and that of the metals $=13.5$ to $14.5 \times 10^{-6} /{ }^{\circ} \mathrm{C}$. The difference of $0.5 \times 10^{-6} /{ }^{\circ} \mathrm{C}$ causes the metal to contract a little more than the ceramic during cooling post-firing. This extracontraction of metal puts the ceramic under slight residual compression, which makes it less sensitive to applied tensile forces. ${ }^{7}$

\section{iv. Palladium-Silver ( $P d-A g$ ) alloys}

In 1974 the first "gold-free" noble metal, metal-ceramic alloys (Pd-Ag alloys) were introduced. These were specifically developed as an economical alternative to the expensive gold-based alloys. Their elastic modulus (95 to $117 \mathrm{GPa}$ ) is also the most favorable of all noble metal, metalceramic alloys. ${ }^{9}$

\section{Disadvantage}

Due to their high silver content, $\mathrm{Pd}-\mathrm{Ag}$ alloys produce more porcelain discoloration. Therefore, barring posterior restorations, experience may be necessary in fabrication of fixed partial restorations. ${ }^{7}$

\section{v. High-Palladium alloys}

Several types of high-palladium alloys were introduced in the 1980 s. $^{7}$ These alloys were primarily developed for economic reasons. They also addressed biocompatibility concerns of nickel-based casting alloys and minimized the porcelain discoloration seen with Pd-Ag alloys. The highpalladium alloys have more palladium ( $>70 \mathrm{wt} \%$ ) than the Pd-Ag alloys. In time the price volatility of palladium (by 2000) led to the use of other alloys. The most popular types have been $\mathrm{Pd}-\mathrm{Cu}, \mathrm{Pd}-\mathrm{Co}$, and Pd-Ga. ${ }^{10}$

\section{Palladium-Copper (Pd-Cu) Alloys}

Though copper present in gold based metal-ceramic alloys, has been reported to cause porcelain discoloration and bonding problems, the same problem is not seen with highpalladium copper-containing alloys. Addition of copper and indium has been reported to decrease the solid solubility of gallium in palladium, causing the eutectic reaction to occur at lower weight percentages of gallium. ${ }^{10}$ It is suggested that this provides excellent hardening and strengthening, as the eutectic constituent is formed in greater amounts. ${ }^{10}$

This can, however, lead to problems during prosthesis fabrication using first-generation Pd-Cu alloys as their high yield strengths (550 to $1100 \mathrm{MPa}$ ) and hardnesses (Diamond pyramid hardness number $=350$ to $400 \mathrm{~kg} / \mathrm{mm}^{2}$ ) make them difficult to finish and polish. ${ }^{10}$ Also, some $\mathrm{Pd}-\mathrm{Cu}$ alloys have low sag resistance (deformation is approximately $1.8 \mathrm{~mm} / \mathrm{min}$ at a bending stress of $19.6 \mathrm{MPa}$ and $1000^{\circ} \mathrm{C}$ ) due to the alloys' poor creep resistance at high stress levels and temperatures which is close to porcelain's glass transition temperature. ${ }^{11}$

\section{Palladium-Cobalt (Pd-Co) Alloys}

The Pd-Co alloys have had limited use.

\section{Disadvantage}

The chief disadvantage of Pd-Co alloys is their tendency to form a dark oxide layer, ${ }^{10}$ which compromises porcelain esthetics. In addition, it has been reported that Pd-Co alloys have lower porcelain bond strengths than $\mathrm{Pd}-\mathrm{Cu}$ alloys. ${ }^{12}$ An adequate bond occurs, when the fracture stress is more 
than $25 \mathrm{MPa}$; however, many metal-ceramic systems have values of $40-60 \mathrm{MPa}{ }^{12}$

\section{Palladium-Gallium (Pd-Ga) Alloys}

The Pd-Ga alloys produce oxide layers that have less capability for ceramic bonding than $\mathrm{Pd}-\mathrm{Cu}$ alloys. ${ }^{7}$

One specific type of Pd-Ga alloy, the palladium-galliumsilver (Pd-Ga-Ag) alloy, is a recently introduced noble metal, metal-ceramic alloy. This alloy was formulated to have a lighter-colored oxide layer than the $\mathrm{Pd}-\mathrm{Cu}$ alloys and is thermally compatible with some lower-expansion porcelains. Compared to other high-palladium alloys, the Pd-Ga-Ag alloys are softer. Though their physical properties appear adequate, more clinical data are necessary to confirm their successful performance. ${ }^{7}$

Table 1 showing properties of noble metal alloys.

\section{Base-metal alloys}

Use of base metal alloys in implant restorations has not been popular due to the potential for corrosion between dissimilar metals. ${ }^{13}$

Two main categories of base-metal metal-ceramic alloy systems exist: Nickel based and cobalt based. Alloys in both systems contain chromium as their second largest constituent and depend upon it for corrosion resistance. However, they react more with their environment compared to noble metal alloys. ${ }^{7}$ Base metal alloys have excellent physical properties. For example, they exhibit the highest modulus of any alloy type used for cast restorations. ${ }^{14}$ For metal-ceramic use, base-metal alloys have been reported to have better castability than noble-metal alloys,${ }^{12}$ but they tend to form thicker and darker oxide layers that may present esthetic problems. ${ }^{14}$

\section{i. Nickel-Chromium ( $\mathrm{Ni}$-Cr) alloys}

These alloys are harder than noble alloys, but usually have lower yield strengths (255 to $730 \mathrm{MPa}$ ). They also have higher elastic modulii (150 to $210 \mathrm{GPa}$ ), and it was hoped that thinner copings and frameworks would result. They have much lower densities ( 7 to $8 \mathrm{gm} / \mathrm{cm}^{3}$ ) and generally higher casting temperatures $\left(1300\right.$ to $\left.1450^{\circ} \mathrm{C}\right)$. Adequate casting compensation is sometimes a problem, as is the fit of the coping. ${ }^{7}$

\section{ii. Cobalt-Chromium (Co-Cr) alloys}

Cobalt is the main constituent of cobalt-based metal-ceramic alloys, with chromium added for strength and to provide corrosion resistance via passivation. Cobalt-Chromium alloys are the most common base-metal alternative for patients who are allergic to nickel. ${ }^{14} \mathrm{~W}$ ith the exception of titanium alloys, the Co-Cr alloys have the highest melting ranges of casting alloys, which make them difficult to be manipulated in the laboratory. ${ }^{14}$

Table 2 showing properties of base metal alloys.

\section{Polymers}

Theoretical considerations and in vitro experiments suggest that an occlusal material with a low modulus of elasticity such as acrylic resin (elastic modulus $=3.8 \mathrm{GPa}$ ) may dampen occlusal impact forces, thereby decreasing its effect

Table 1: Properties of noble metal alloys

\begin{tabular}{lllllll}
\hline Type & $\begin{array}{l}\text { Ultimate tensile } \\
\text { strength (MPa) }\end{array}$ & $\begin{array}{l}\text { 0.2\% yield } \\
\text { strength (MPa) }\end{array}$ & $\begin{array}{l}\text { Elastic } \\
\text { modulus }(\mathrm{GPa})\end{array}$ & $\begin{array}{l}\text { Elongation } \\
(\%)\end{array}$ & $\begin{array}{l}\text { Diamond } \\
\text { pyramid hardness } \\
\left(\mathrm{kg} / \mathrm{mm}^{2}\right)\end{array}$ \\
\hline Au-Pt-Pd & $480-500$ & $400-420$ & $81-96$ & $3-10$ & $175-180$ & 1150 \\
Au-Pd & $700-730$ & $550-575$ & $100-117$ & $8-16$ & $210-230$ & $1320-1330$ \\
Au-Pd-Ag & $650-680$ & $475-525$ & $100-113$ & $8-18$ & $210-230$ & $1320-1350$ \\
Pd-Ag & $550-730$ & $400-525$ & $95-117$ & $10-14$ & $185-235$ & $1310-1350$ \\
Pd-Cu & $690-1300$ & $550-1100$ & $94-97$ & $8-15$ & $350-400$ & $1170-1190$ \\
\hline
\end{tabular}

Table 2: Properties of base metal alloys

\begin{tabular}{lllllll}
\hline Type & $\begin{array}{l}\text { Ultimate tensile } \\
\text { strength (MPa) }\end{array}$ & $\begin{array}{l}0.2 \% \text { yield } \\
\text { strength (MPa) }\end{array}$ & $\begin{array}{l}\text { Elastic } \\
\text { modulus (GPa) }\end{array}$ & $\begin{array}{l}\text { Elongation } \\
(\%)\end{array}$ & $\begin{array}{l}\text { Diamond } \\
\text { pyramid hardness } \\
\left(\mathrm{kg} / \mathrm{mm}^{2}\right)\end{array}$ & $\begin{array}{l}\text { Casting } \\
\text { temperature }\left({ }^{\circ} \mathrm{C}\right)\end{array}$ \\
\hline $\mathrm{Ni}-\mathrm{Cr}$ & $400-1000$ & $255-730$ & $150-210$ & $8-20$ & $210-380$ & $1300-1450$ \\
$\mathrm{Co}-\mathrm{Cr}$ & $520-820$ & $460-640$ & $145-220$ & $6-15$ & $330-465$ & $1350-1450$ \\
\hline
\end{tabular}


on the bone-implant interface. However, the protective role of resin for the bone-implant interface has not been well supported by finite element analysis. More clinical complications have been reported, when acrylic resin or composite is used on occlusal surfaces such as screw loosening, resin fracture and resin wear. ${ }^{15}$

i. Acrylic resin

Skalak ${ }^{6,16}$ hypothesized that an occlusal material with a low modulus of elasticity might dampen the occlusal impact forces, thereby decreasing its effect on the bone-implant interface. Thus, he suggested use of acrylic resin teeth, and indicated that such a resilient element could be placed elsewhere in the restoration as well.

However, the results of an in vivo study by Bassit et al. ${ }^{17}$ showed that the resilience of an acrylic resin veneer is insufficient to cause significant change in the force transmission through the prosthesis as compared to a ceramic veneer.

\section{Advantages}

Although, acrylic resin has many disadvantages, it has several merits over porcelain fused to metal (PFM) bridges. Although, it cannot dampen shock, it can delay the time of the shock rising to peak force. ${ }^{17}$ Resin material may be better for maxillary long span bridges than the heavier porcelain fused to metal. It also can be easily repaired chairside, if it fractures. This is an advantage considering that porcelain fracture is one of the most frequent complications of conventional and implant fixed partial restorations. ${ }^{18}$

\section{Disadvantages}

They have poor wear resistance. Ceramic and composite wears at roughly 12 to 14 micron/year (height) and 10 to $12 \mathrm{micron}^{3} /$ year (volume). Resin wears at 50 micron/year (height) and 45 micron/year (volume). ${ }^{19}$

Their excessive thermal expansion $\left(81 \times 10^{-6} /{ }^{\circ} \mathrm{C}\right)$ and contraction lead to the development of stresses, when hot and cold beverages and foods are consumed. ${ }^{7}$
Although, they have good initial esthetics, they discolor over time.

Hence, acrylic resin is used as an implant restorative material only, when the space available is unfavorable for ceramic fused-to-metal or when the patient wants to reduce the cost of treatment. It is also used as an interim prosthesis 15 and in hybrid prosthesis. However, they require frequent relines, tooth replacement (in 20 to $90 \%$ cases), and cause screw loosening and fractures ( 3 to $8 \%$ in five years). ${ }^{20}$

\section{ii. Composite resins}

Conventional acrylic resin facing materials exhibit poor wear resistance and may not maintain the established occlusal anatomy. ${ }^{21}$

Fiber reinforced composite (FRC/laboratory processed resin) can be a prospective alternative for implant prosthetic materials due to its higher modulus of elasticity (28.5 GPa) and abrasion resistance compared to conventional composite. Fiber reinforced composite is also called ceromer or polyglass because it has properties of both resin and porcelain. It has greater strength because of the fusion between filler and matrix, which makes its abrasion resistance similar to that of natural teeth. It has superior color stability compared to traditional composites due to low water adsorption. The modulus of elasticity of this material is comparable to dentin (12 to $19 \mathrm{GPa}$ ) and hence can be used without metal framework. FRC can be repaired chair side and it exhibits minimal shrinkage as manipulation of the material is completed on the working die, whereas porcelain goes through high temperature sintering on a metal substructure. ${ }^{1}$ Behr ${ }^{22}$ reported the possibility of using FRC for fixed partial restorations on dental implants as an alternative to conventional implant prostheses.

Table 3 showing properties of composite resin and acrylic resin.

\section{Disadvantages}

Composites absorb water and thus have decreased surface hardness and wear resistance. Hence, there is greater potential for discoloration by water soluble stains. Solubility

Table 3: Properties of composite resin and acrylic resin

\begin{tabular}{lllll}
\hline Property & $\begin{array}{l}\text { Laboratory } \\
\text { composite }\end{array}$ & Acrylic resin & Enamel & Dentin \\
\hline Compressive strength (MPa) & 613 & 427 & $200-442$ & $232-311$ \\
Flexural strength (MPa) & 218 & 93 & $80-90$ & $138-270$ \\
Modulus of elasticity (GPa) & 28.5 & 6.1 & $47-84$ & $12-19$ \\
Vickers hardness (VH) & 190 & 42 & $270-366$ & $57-76$ \\
\hline
\end{tabular}


of resin composites ranges from 1.5 to $2 \%$ of the original material weight. Elements from filler particles dissolve in water to varying degrees and are detected in quantities as high as $180 \mu \mathrm{mol} / \mathrm{gm}^{8}{ }^{8}$

Ceramics and metals are characterized by strong bonds between atoms, and the secondary bonds play an insignificant role in their properties. As a result, most ceramics and metals expand relatively little when heated. i.e. their coefficient of thermal expansion is relatively low (4 to $14 \times 10^{-6} /{ }^{\circ} \mathrm{C}$ ). Polymers, however, are characterized by strong bonds within polymer chains and weak bonds between polymer chains. As a result, when a polymer is heated, the chains move farther apart accounting for a high coefficient of thermal expansion $\left(30 \times 10^{-6} /{ }^{\circ} \mathrm{C}\right){ }^{8}$

Histological studies of the effect of residual monomer molecules on pulp tissue have shown a moderate degree of cytotoxicity, even in low concentrations. ${ }^{8}$

Thus, inspite of having improved properties as compared to traditional composites, their properties are still inferior to ceramics and metals.

\section{Ceramics}

Due to increasing interest in esthetics and concerns about toxic and allergic reactions to certain alloys, patients and dentists have been looking for metal-free tooth-colored restorations. Therefore, the development of high strength dental ceramics, which appear to be less brittle, have less tensile strength, and are less subject to time dependent stress failure, has dominated the latter part of the twentieth century. ${ }^{23-25}$

A study was conducted to define the fracture rate of implant supported metal-ceramic restorations delivered in private practice, and to identify if a restoration's contact during eccentric mandible movements has any influence on ceramic fracture rates. It was noted that ceramic veneer fracture rate was $6.7 \%$, and a conclusion that a restoration's contact during eccentric excursions may significantly enlarge fracture rates was made. ${ }^{26}$

Because of their specific mechanical properties, allceramic restorations demonstrate a lower fracture resistance than ceramic restorations supported by metal substructures. To avoid these defects, 2 types of industrially prefabricated high-strength all-ceramic abutments with improved optical and mechanical properties are made available for implants: a densely sintered high-purity alumina $\left(\mathrm{Al}_{2} \mathrm{O}_{3}\right)$ ceramic, and a $\mathrm{Y}_{2} \mathrm{O}_{3}$-partially- stabilized $\mathrm{ZrO}_{2}$-ceramic implant abutment. However, the $\mathrm{ZrO}_{2}$ abutments are more than twice as resistant to fracture as the $\mathrm{Al}_{2} \mathrm{O}_{3}$-abutments. ${ }^{27}$
Zirconia is widely used to build prosthetic devices because of its good chemical properties, dimensional stability, high mechanical strength, toughness, and a Young's modulus (210 GPa) similar to that of stainless steel alloy (193 GPa). The mechanical properties of zirconia are the highest ever reported for any dental ceramic. The high initial strength and fracture toughness of zirconia results from a physical property of partially stabilized zirconia known as transformation toughening. ${ }^{28,29}$ In vitro studies of zirconium dioxide specimens demonstrate a flexural strength of 900$1200 \mathrm{MPa}$ and a fracture toughness of 9 to $10 \mathrm{MPa} / \mathrm{m}^{2}$. On the other hand, its ability to transmit light and its white color, similar to the color of natural teeth, makes it useful in esthetic restorations of the oral cavity. ${ }^{30}$

Zirconia-based fixed partial restorations have a wider application than other ceramics, because they can be used on molars. Although, some manufacturers suggest them for full-arch restorations, five-unit fixed partial restorationss are reported to be the maximum possible. ${ }^{31}$

The success rate of this zirconia framework in the 5year follow-up was $97.8 \%{ }^{30}$ The most frequent technical problem in studies of zirconia reconstructions is chipping or cracking of the veneer ceramic. These results were attributed to low or moderate bond strength between zirconia frame works and veneering ceramics. It can be concluded that various veneering ceramics available for zirconia possess insufficient mechanical properties. ${ }^{32}$

Lithium disilicate is a high strength ceramic material with 360 to $400 \mathrm{MPa}$ of flexural strength. When fabricated to full contour or in a monolithic state, lithium disilicate is extremely durable. Failures in zirconia veneered restorations are the result of a very weak porcelain material (flexural strength of $90 \mathrm{MPa}$ ) having masticatory forces exerted upon it. The zirconia substructure with a flexural strength of 1,000 MPa remains in tact but the failure of the layering porcelain ultimately causes a failure of the restoration. ${ }^{33}$

With monolithic lithium disilicate, the force of mastication is applied on a 360 to $400 \mathrm{MPa}$ material. This strength is homogenous throughout the entire restoration. Several tests have demonstrated that the monolithic lithium disilicate is incredibly durable and that the zirconia veneered restorations fail with less load and fewer chewing cycles. ${ }^{33}$

However, esthetic outcome of such machinable blocks may be a concern. In a study, regardless of the fabrication method the crowns were esthetically acceptable in all the patients. The mean values for the layering technique and for the machined restorations did not differ significantly. 
Thus, it was documented, that machinable blocks could attain esthetically satisfying results. ${ }^{34}$

\section{CONCLUSION}

With newer materials being introduced in implant dentistry, it is imperative to acquire knowledge about various materials available and understand the factors, which will contribute to the success or failure of the restorations. To weigh the advantages and disadvantages of various materials before proceeding with the treatment would be invaluable towards making a prudent decision in rendering the appropriate restoration to the patient in terms of optimal health, esthetics and function.

\section{REFERENCES}

1. HK Kim, SJ Heo, JY Koak, SK Kim. In vivo comparison of force development with various materials of implant-supported prostheses Journal of Oral Rehabilitation 2009;36:616-25.

2. Roman M Cibirka, Michael E Razzoog, Brien R Lang, Christian $S$ Stohler. Determining the force absorption quotient for restorative materials used in implant occlusal surfaces. J Prosthet Dent 1992;67:361-64.

3. Enrico Conserva, Maria Giambattista Ravera, Francisco Pera, et al. The use of a masticatory robot to analyze the shock absorption capacity of different restorative materials for prosthetic implants: A preliminary report. Int J Prosthodont 2009;22:53-55.

4. Juodzbalys G, Kubilius R, Eidukynas V, Raustia AM. Stress distribution in bone: Single-unit implant prosthesis veneered with porcelain or a new composite material. Implant Dent 2005;14:166-75.

5. Ciftci Y, Canay S. The effect of veneering materials on stress distribution in implant supported fixed prosthetic restorations. Int J Oral Maxillofac Implants 2000;15:571-82.

6. Skalak R. Biomechanical considerations in osseointegrated prostheses. J Prosthet Dent 1983;49:843-48.

7. Phillips' Science of dental materials (11th ed).

8. O'Brien WJ. Dental Materials and Their Selection (3rd ed). Chicago, IL, Quintessence 2002;204-07.

9. Naylor WP. Introduction to Metal-ceramic Technology. Chicago, IL, Quintessence 1992;28-38.

10. Carr AB, Brantley WA. New high-palladium casting alloys Part 1. Overview and initial studies. Int J Prosthodont 1991;4:265-75.

11. Anusavice KJ, Shen C, Hashinger D. Interactive effect of stress and temperature on creep of PFM alloys. J Dent Res 1985;64:1094-99.

12. O'Connor RP, Mackert JR, Myers ML, et al. Castability, opaque masking, and porcelain bonding of 17 porcelain-fused-to-metal alloys. J Prosthet Dent 1996;75:367-74.

13. Thomas D Taylor, John R Agar, Theodora Vogiatzi. Implant prosthodontics: Current perspectives and future directions. International Journal of Oral and Maxillofacial Implants 2000;15(1):66-75.

14. Wataha JC, Messer RL. Casting alloys. Dent Clin North Am 2004;48:499-512.

15. Linish Vidyasagar, Peteris Apse. Restorative factors that affect the biomechanics of the dental implant, Baltic Dental and Maxillofacial Journal 2003;5:123-28.
16. Skalak R. Aspects of biomechanical consideration. In: Branemark P-I, Zarb GA, Albrektsson T (Eds). Tissue-integrated prostheses: Osseointegration in clinical dentistry. Chicago: Quintessence 1985;117-28.

17. Roger Bassit, Hakan Lindstrom and Bo Rangert. In vivo registration of force development with ceramic and acrylic resin occlusal materials on implant supported prostheses. Int J Oral Maxillofac Implants 2002;17:17-23.

18. Pjetursson BE, Sailer I, Zwahlen M, Ha“mmerle CH. A systematic review of the survival and complication rates of allceramic and metal-ceramic reconstructions after an observation period of at least 3 years. Part I: Single crowns. Clin Oral Implants Res. 2007;18(Suppl 3):73-85.

19. Anselm Wiskott HW, Perriard J, Scherrer SS, Dieth S, Belser UC. In vivo wear of three types of veneering materials using implant-supported restorations: A method evaluation. Eur J Oral Sci. 2002 Feb;110(1):61-67.

20. Bradley A. Purcell, Edwin A. Mc Glumphy, Julie A. Holloway and Frank M. Beck: Int J Oral Maxillofac Implants 2008;23: 847-57.

21. Shiro Suzuki, Eiichi Nagai, Yohsuke Tiara, Yoshito Minesaki. In vitro wear of indirect composite restoratives. J Prosthet Dent 2002;88:431-36.

22. Behr M, Rosentritt M, Lang R, Handel G. Glass fiber reinforced composite fixed partial dentures on dental implants. J Oral Rehabil 2001;28:895-902.

23. Qualtrough AJ, Piddock V. Ceramics update. J Dent 1997;25: 91-95.

24. Strub JR, Beschnidt SM. Fracture strength of 5 different allceramic crown systems. Int J Prosthodont 1998;11:602-09.

25. McLean JW. Evolution of dental ceramics in the twentieth century. J Prosthet Dent 2001;85:61-66.

26. Tomas Linkevicius, Eugenijus Vladimirovas, Simonas Grybauskas, Algirdas Puisys, Vygandas Rutkunas. Veneer fracture in implant-supported metal-ceramic restorations. Part I: Overall success rate and impact of occlusal guidance. Stomatologija, Baltic Dental and Maxillofacial Journal. 2008;10:33-139.

27. Murat Yildirim, Horst Fischer, Rudolf Marx, Daniel Edelhoff. In vivo fracture resistance of implant-supported all-ceramic restorations. J Prosthet Dent 2003;90:325-31.

28. Piconi C, Maccauro G. Zirconia as a ceramic biomaterial. Biomaterials 1999;20:1-25.

29. Garvie RC, Hannink RHJ, Pascoe RT. Ceramic steel. Nature 1975;258:703-04.

30. Ahmad I. Yttrium-partially stabilized zirconium dioxide posts: An approach to restore coronally compromised nonvital teeth. Int J Periodontics Restorative Dent 1998;18:455-65.

31. Larsson C, Vult von Steyern P, Sunzel B, et al. All-ceramic two to five-unit implant-supported reconstructions. A randomized, prospective clinical trial. Swed Dent J 2006;30:45-53.

32. Zeynep O"zkurt, Ender Kazazoglu: Clinical Success of Zirconia in Dental Applications Journal of Prosthodontics xx 2009;1-5.

33. Ozgur Inan, Asli Secilmis, Oguz Eraslan. Effect of pontic framework design on the fracture resistance of implantsupported all ceramic fixed partial dentures. J Appl Oral Sci 2009;17(5):533-38.

34. Herrguth M, Wichmann M, Reich S. The aesthetics of all-ceramic veneered and monolithic CAD/CAM crowns. J Oral Rehabil 2005. 